\title{
THE USE OF STREPTOKINASE BILE SALT BROTH FOR CLOT CULTURES IN THE DIAGNOSIS OF ENTERIC FEVER
}

\author{
BY \\ JOHN C. THOMAS, K. C. WATSON, AND A. S. HEWSTONE \\ From the Central Pathological Laboratory, Durban, South Africa
}

(RECEIVED FOR PUBLICATION MARCH 27, 1953)

In spite of the constant reiteration in almost every publication on typhoid fever that bacteriological examination of the blood is the diagnostic method of choice in the early stage of the disease, coupled with the steady stream of post-war publications emphasizing the uselessness of the Widal test at this time, it is remarkable how many requests for the latter are still made as the primary test and how few for the former. The determining factor is probably convenience, and although it has been possible to insist on blood cultures being done in hospital practice, it will be a long time before a similar routine can be effectively established in the mission outstations or in the field. A practical routine for the demonstration of the causative organism in the clotted blood specimen sent for the Widal test would turn a probably useless specimen into one of certain diagnostic value.

As early as 1906 Fornet demonstrated that clot culture was a practical procedure. We know that many tropical and sub-tropical laboratories use such a technique, as we have done in West Africa, India, and China, but the only references to it in the literature of the last 30 years appear to be those of Felix (1924) and Downie and Fairbrother (1934).

In the past it has been our practice to add the whole blood clot after separation of the serum (representing $4-5 \mathrm{ml}$. blood) to $10 \mathrm{ml} .0 .5 \%$ sodium taurocholate broth in a screw-capped bottle, and, after vigorous shaking, to incubate and plate out on to Wilson and Blair's medium daily. A preliminary series of duplicate experiments showed that bile salt broth was preferable to "selenite" $F$ broth, as the latter was inhibitory during the long incubation period required. At first the clots were incubated for 10 days before discarding, and the majority of those yielding a growth of $S$. typhi did so on the sixth or seventh day. Following the observations of Batty Shaw and Mackay (1951) that 10 days' incubation was insufficient for enteric blood cultures, we extended the period to 21 days and recovered positive clot cultures in the third week. This time lag, however, negatived the value of the examination from the clinical aspect, and often only served to determine the diagnosis in retrospect.

It was noted that even after 21 days' incubation more than half of the tubes still contained appreciable volumes of clot, and we considered it probable that bacteria were trapped in the clot and unable to grow, especially in those cases in which there was only a low degree of bacteraemia. Various methods of breaking down the clot were tried, such as trituration with sterile glass rods, mechanical shaking, and the addition of saponin from $0.1 \%-10 \%$ concentration, but none materially shortened the time of appearance of positive cultures. The increasing clinical use of the fibrinolytic streptococcal enzyme streptokinase suggested that it might prove of value here.

\section{Effect of Streptokinase on Clot Cultures}

Ten $\mathrm{ml}$. volumes of bile salt broth were prepared with concentrations of streptokinase* varying from $\delta$ 25 to 10,000 units per $\mathrm{ml}$. To each was added $3 \mathrm{ml}$. sterile blood clot, and these, together with control tubes without streptokinase, were incubated at $37^{\circ} \mathrm{C}$. 글 After 24 hours there was no apparent lysis in the $D$ control tubes or in those containing 25 and 10,000 . units of streptokinase. The intermediate enzyme con- N centrations $(50,100,250,500$, and 1,000 units per ml.) all showed partial lysis. Lysis was complete in these $N$ tubes at 36 hours and was partial in the 25- and 쓸 10,000 -unit tubes, while the control tubes still showed $\sigma$ no lysis. Five of the seven control tubes still showed appreciable clot after 14 days' incubation. We accep- $\stackrel{O}{工}$ ted 100 units per $\mathrm{ml}$. as a suitable concentration for $\Phi$ lysing the normal Widal clot in 36 hours, and used $\stackrel{?}{+}$ this concentration for all subsequent work. Strepto- 0 kinase cannot be used in "selenite" $F$ medium, as selenium inhibits enzyme action. * The streptokinase used was kindly supplied by the Lederle $\sigma$
Laboratories Division of the American Cyanamid Co. in the form of a white powder containing 100,000 units streptokinase and $25,000 \mathrm{O}$ units streptodornase per vial. A considerable amount of hyaluron-O idase is also present. 


\section{Effect of Streptokinase on S. typhi}

Similar series of streptokinase-bile salt broth tubes were set up and inoculated with one loopful of a six-hour digest broth culture of $S$. typhi. Twentyone recently isolated virulent strains together with the stock laboratory strains 901-0, Ty2, and Bhatnagar ViI were tested. After overnight incubation no inhibition of growth was found when compared with the control tubes with concentrations of streptokinase up to 250 units per $\mathrm{ml}$. There was a slight inhibition at 500 units per $\mathrm{ml}$. and complete inhibition at 1,000 units per $\mathrm{ml}$.

\section{Stability of Streptokinase in Bile Salt Broth}

The inhibitory action of 1,000 units per $\mathrm{ml}$. of streptokinase was used to estimate its stability in bile salt broth. Two series of bile salt broth tubes were prepared containing this concentration of streptokinase, one being left at room temperature (about $22^{\circ} \mathrm{C}$.), and the other stored at $4^{\circ} \mathrm{C}$. One bottle of each series was inoculated daily for 21 days, together with a control, with one drop of an overnight culture of $S$. typhi, and both were incubated overnight. In every case inhibition of growth in the streptokinase tubes was complete. The conclusion that there was no appreciable loss of enzyme activity over this period was confirmed by the more accurate assay technique described by Cathie (1949).

\section{Recovery of S. typhi from Artificially Infected Clots}

A number of artificially infected clots of $6 \mathrm{ml}$. volume were prepared, each containing approximately 100 organisms of a recently isolated strain of S. typhi. These were bisected under sterile conditions and the halves inoculated into $10 \mathrm{ml}$. bile salt broth and $10 \mathrm{ml}$. bile salt broth containing 100 units per ml. streptokinase respectively, each tube thus containing approximately 50 organisms embedded in $3 \mathrm{ml}$. blood clot. The tubes were incubated and plated out daily for 14 days on to Wilson and Blair's medium. Twentyfour such clots were tested with the following results:

\begin{tabular}{c|c|c|c|c}
\hline Day & \multicolumn{2}{|c|}{$\begin{array}{c}\text { Streptokinase } \\
\text { Bile Salt Broth }\end{array}$} & \multicolumn{2}{|c}{$\begin{array}{c}\text { Bile Salt } \\
\text { Broth }\end{array}$} \\
\cline { 1 - 4 } \cline { 3 - 4 } & Positive & Negative & Positive & Negative \\
\hline 1 & 19 & 5 & 10 & 14 \\
2 & 20 & 4 & 10 & 14 \\
3 & 24 & 0 & 10 & 14 \\
4 & - & - & 14 & 10 \\
7 & - & - & 15 & 9 \\
14 & - & - & 15 & 9 \\
\hline
\end{tabular}

Thus $100 \%$ of the streptokinase broth cultures gave positive isolations within three days, the comparative figure for bile salt broth alone being $41.5 \%$, while $37.5 \%$ of the latter were still negative after 14 days.

\section{Viability of S. typhi in Blood Clot}

Twenty-four artificially infected clots were prepared and bisected as above. One-half of each was inoculated into streptokinase broth, and $S$. typhi was recovered from these in every case. Of the remaining halves, 12 were stored at $37^{\circ} \mathrm{C}$. and 12 at $4^{\circ} \mathrm{C}$. for 14 days and then inoculated into streptokinase broth. $S$. typhi was recovered from all the refrigerated clots, but failed to grow from the $37^{\circ} \mathrm{C}$. series within 14 days. It is probable, therefore, that part at least of the cause of our not being able to recover viable organisms from clots which have been sent by post or rail in the Natal climate lies in a direct action of the blood upon the bacteria. This point is being investigated further.

\section{Application to Routine Diagnosis}

To investigate the practicability of this method for routine diagnosis 350 clots from Widal specimens sent to this laboratory were cultured in parallel in plain bile salt broth and in bile salt broth containing 100 units per ml. streptokinase. The specimens are received in a sterile $75 \times 12 \mathrm{~mm}$. glass tube with a rubber bung. After separation of serum, the clots are decanted into a sterile petri dish and bisected with two sterile microscope slides, the halves being inoculated into $10-\mathrm{ml}$. volumes of the respective media. Daily subcultures for 14 days are made on to WilsonBlair's bismuth-sulphite agar. By using a numbered template mounted on a sheet of glass illuminated from below and a $5-\mathrm{mm}$. loop, it is possible to spot 25 subcultures on to a standard $90-\mathrm{mm}$. plate. Positive cultures yielded a black ring of growth at the periphery of the spot with the typical metallic sheen after 24 to 36 hours' incubation (Fig. 1). All posi-

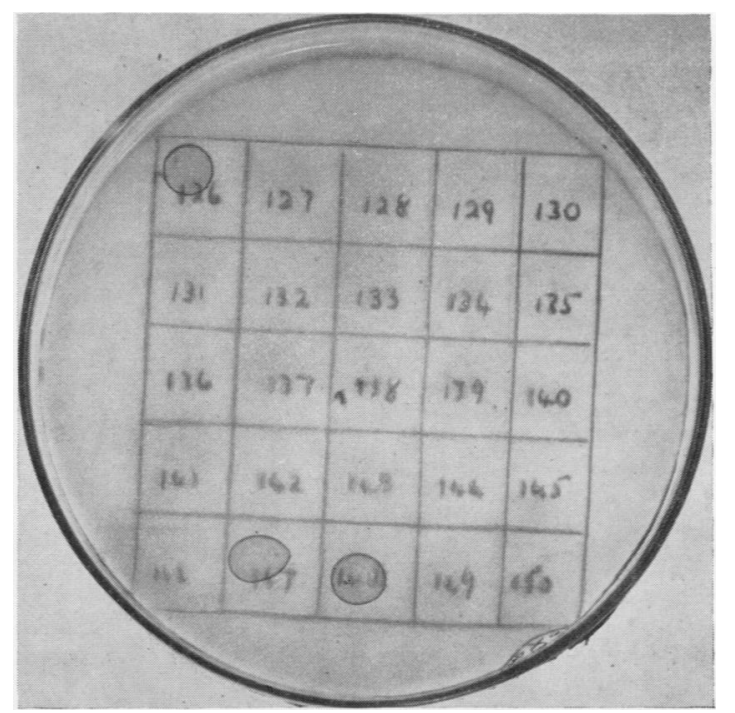

FIG. 1.-Three positive $S$. typhi spot cultures $(126,147,148)$ on Wilson and Blair's medium spotted with 25 cultures. 
tive or suspicious spots are subcultured, and the organism identified in the usual manner. It was found convenient to continue spotting positive cultures throughout the fortnight, as the position of the positive spot on the plate served as an additional check on the accuracy of plating. The whole investigation required nearly 10,000 spot cultures.

Typhoid is endemic in the native reserves of Natal, and normally some 300 isolations are made annually in this laboratory. Unfortunately, this investigation was made in the two winter months when the incidence is at its lowest, so that only 20 cases were proved bacteriologically during this period. The results, however, appear sufficiently striking to warrant reporting. Of the 20 , one yielded a positive blood culture, showed an $O$ titre of 640 , but failed to give a positive clot culture in either of the two media. The blood culture and Widal specimens were taken at the same time. This is the only case in which a positive blood culture and negative clot culture has been observed. In one other case the clot was too small to split and was inoculated into streptokinase broth only, yielding a growth of $S$. typhi on the first day. Of the remaining 18,16 yielded $S$. typhi and two $S$. paratyphi $A$ (Table I).

TABLE I

COMPARISON OF POSITIVE ISOLATIONS IN BILE SALT BROTH WITH AND WITHOUT STREPTOKINASE

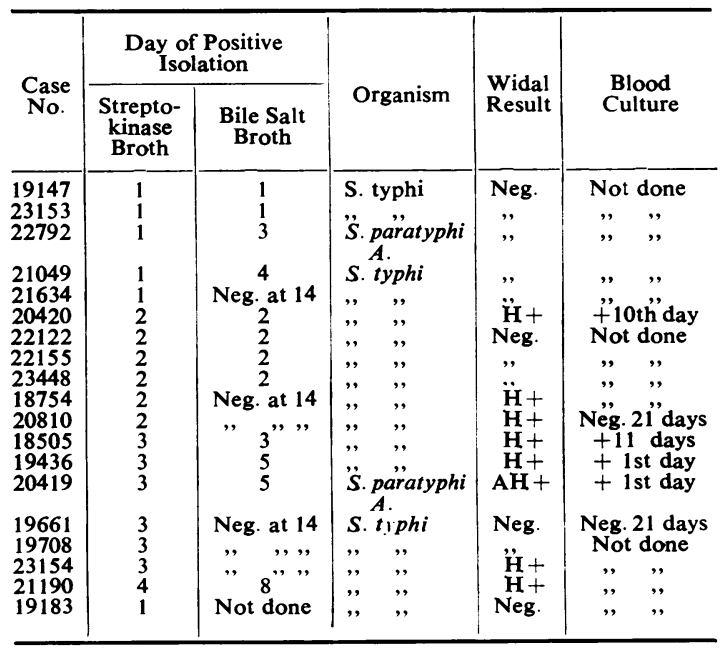

Of the 18 clots, 17 were positive in the first three days in streptokinase broth, while only eight were positive in bile salt broth. The eighteenth was positive on the fourth day in the former; this clot was contaminated and a pure culture of $S$. typhi was only obtained on that day. In plain bile salt broth one became positive on the fourth day, two on the fifth and one on the eighth day, while the remaining six $(33.3 \%)$ were still negative on the fourteenth day. Of the streptokinase isolations, the average time for a positive culture to appear was 2.1 days. Only two- thirds of the parallel bile salt cultures were positive, becoming thus at an average of 3.2 days.

The Widal tests were positive at a "diagnostic" 으 titre in eight of the 19 , the remaining 11 being negative. Parallel blood cultures in $35 \mathrm{ml}$. bile salt broth $\frac{\bar{\omega}}{\partial}$ were sent in only six cases. Of these, two were posi- $\mathbb{\mathbb { Q }}$ tive on the first day, two on the tenth-eleventh day, and two negative on the twenty-first day. Visible $\backsim$ clot was still present at this time. In both of the $\overrightarrow{0}$ negative cases the bile salt clot culture was nega- $\overrightarrow{\vec{C}}$ tive on the fourteenth day, while the streptokinase $\vec{\omega}$ cultures were positive on the second and third day respectively.

\section{Discussion}

Although this series is small, we feel that the $\overrightarrow{0}$ use of streptokinase bile salt broth for clot culture offers an additional practical technique for the positive bacteriological diagnosis of enteric fever. $\vec{T}$ The causative organism was isolated within four $\mathbb{D}$ days from the residual clot in 19 of 350 specimens sent for Widal examination, the latter being negative in eleven. In the two months before the $\overrightarrow{-}$ present experiment, when clots were cultured in bile salt broth alone, 32 positive isolations were ${ }^{+}$ made from 346 specimens from clot cultures, $25 \%$ of these showing negative Widal reactions. The overall gain in diagnosis was thus 36 in the total of 50 isolations.

The action of streptokinase appears to be the $\stackrel{\mathbb{Q}}{\mathscr{2}}$ purely enzymatic one of dissolving the clot rapidly $\overrightarrow{\overrightarrow{0}}$ and allowing the entrapped organisms free access 3 to their nutrient medium. This is normally complete within 24 to 36 hours, so that positive cultures? may be expected and occur within the first three days of incubation. This rapid result compares:favourably with those of Batty Shaw and Mackay, 3 . who, in analysing 192 blood cultures in taurocholate broth, found the average time of incuba- $\frac{\text { 을 }}{3}$ tion to yield a positive result was four to five days, 0 and $17 \%$ did not become positive until nine to eleven days. The fact that blood clot itself exerts a bactericidal action on $S$. typhi at $37^{\circ} \mathrm{C}$. is of importance, and emphasizes the need for rapid $N$ liberation of the organism from it. It is probable that this factor is responsible for the failures to으 isolate the organism in simple bile salt media from ${ }_{\sigma}^{\omega}$ both clot cultures and blood cultures in which clotting has occurred, as the lytic action of sodiume taurocholate is small. The addition of an anti-霖 coagulant such as sodium citrate or a lytic agent such as saponin to the commonly used bile salt $\frac{-}{\circ}$ blood culture media would appear to be mandatory.

The availability of chloramphenicol has empha sized the need for early diagnosis of enteric fever, $\bar{x}$ and in hospital practice there can be no question 
that early and, if necessary, repeated blood culture is the method of choice. Streptokinase broth offers a practical method of blood culture for domiciliary use and should materially assist in rapid diagnosis when only a clotted specimen of blood can be obtained.

\section{Summary}

Parallel cultures in streptokinase bile salt broth (100 units per ml.) and in plain bile salt broth have been made on the residual blood clot from 350 specimens submitted for a Widal test.

In 19 cases $S$. typhi or $S$. paratyphi $A$ was isolated from streptokinase broth within four days, the average time to produce a positive result being 2.1 days.
Bile salt broth cultures yielded positive results in 12 cases after one to eight days' incubation (average 3.2 days), and remained negative after 14 days in six cases which gave positive streptokinase broth isolations. Similar results were obtained with artificially infected clots.

Streptokinase is stable in bile salt broth for at least 14 days.

The use of streptokinase bile salt broth offers a rapid means of diagnosing enteric fever in domiciliary practice when only a clotted blood specimen can be obtained.

\section{REFERENCES}

Batty Shaw, A., and Mackay, H. A. F. (1951). J. Hyg., 49, 315.

Cathie, I. A. B. (1949). Lancet, 1, 441.

Downie, A. W., and Fairbrother, R. W. (1934). Brit. med. J., 1, 55.

Felix, A. (1924). J. Immunol., 9, 115. 